\title{
Circulating IgG antibody against FOXP3 may be a potential biomarker for lung cancer ${ }^{*}$
}

\author{
Weili Wang $^{1 \#}$, Leiguang $\mathrm{Ye}^{2 \#}$, Xiaomei $\mathrm{Li}^{2}$, Songlei Guan ${ }^{1}$, Shilong Sun ${ }^{1}$, Meng Wang ${ }^{2}$, \\ Xueqing Guan ${ }^{2}$, Kuang-Hui Lee ${ }^{3}$, Jun Wei ${ }^{1,4}$, Baogang Liu ${ }^{2}$ \\ ${ }^{1}$ Department of Radiobiology, School of Public Health, Jilin University, Changchun, China \\ ${ }^{2}$ Department of Pulmonary Oncology, The Third Affiliated Hospital of Harbin Medical University, Harbin, China; \\ liubaoganghum@gmail.com \\ ${ }^{3}$ Pei-Ling Guan-Si Hospital, Taiwan \\ ${ }^{4}$ Department of Diabetes \& Cardiovascular Science, University of the Highlands \& Islands, Centre for Health Science, Inverness, UK; \\ jun.wei@uhi.ac.uk
}

Received 5 September 2013; revised 2 October 2013; accepted 10 October 2013

Copyright (C) 2013 Weilin Wang et al. This is an open access article distributed under the Creative Commons Attribution License, which permits unrestricted use, distribution, and reproduction in any medium, provided the original work is properly cited.

\section{ABSTRACT}

Background: Forkhead box P3 (FOXP3) has been found to be overexpressed by a range of cancer cells and correlated with prognosis of tumors. This finding raises the possibility that the development of anti-FOXP3 antibody test may be useful for clinical application. Objective: The present work was designed to test whether circulating autoantibody to FOXP3 was altered in lung cancer. Methods: 271 patients with non-small cell lung cancer (NSCLC) and 227 in control subjects matched in age, gender and smoking history were recruited. Circulating antiFOXP3 IgG antibody was tested using an inhouse enzymelinked immunosorbent assay. Results: Student's $t$-test showed that the levels of IgG autoantibody to FOXP3 were significantly higher in patients with NSCLC than control subjects $(t=7.67, P<0.0001)$. Receiver operating characteristic (ROC) analysis showed that the area under the ROC curve (AUC) was 0.70 (95\% Cl $0.65-0.75$, SE \pm 0.024$)$, in which patients at stage 2 had the highest AUC of 0.75 $(95 \% \mathrm{Cl} 0.67-0.81, \mathrm{SE} \pm 0.037)$, with a sensitivity of $31.4 \%$ against a specificity of $90.3 \%$. Analysis of quality control samples gave an inter-assay deviation of $13.3 \%$ among 45 plates tested. Conclusions: Circulating IgG autoantibody to FOXP3 may be a potential biomarker for lung cancer.

Keywords: Autoantibody; Biomarker; FOXP3; Lung

*Competing interests: The authors declared that they had no conflict of interest.

${ }^{\#}$ These two authors contributed equally to this work.
Cancer; Tumor Immunity

\section{INTRODUCTION}

A number of recent studies suggest that circulating autoantibodies to a particular tumor-associated antigen (TAA) are positive in some patients with malignant tumors [1-3] although the TAAs involved in the specific immune response vary among tumor types and among individuals with a tumor. Spontaneous tumor-related antibodies have also been considered as being biomarkers for early diagnosis and prognosis of malignancies $[1,2,4$, 5]. Circulating autoantibodies to TAAs are detectable several years before radiographic detection or incidence screening is able to identify a tumour [6-8]. Early CDTLung was the first autoantibody-based diagnostic tool in lung cancer [9]. It was made with a panel of 7 TAAs and the panel antibody positivity has achieved up $50 \%$ in patients with lung cancer [9]. Autoantibodies to a panel of TAAs have also been reported in breast cancer and the positive rates reported to date range from $30 \%$ to $80 \%$ [5]. While the detection of circulating autoantibodies is a promising way for early diagnosis and prognosis of cancer, the improvement of sensitivity and specificity remains needed. To achieve this goal, it is important to identify new TAAs additive to the current panel. A question to be addressed here is why only a subgroup of patients with cancer develops the humoral immune responses to a particular TAA. It is possible that the human leukocyte antigen class II (HLA-II) genotypes predispose to the development of humoral immune responses to a particular TAA.

Forkhead box P3 (FOXP3) is a member of the forkhead/winged-helix family of transcriptional factors [10]. 
It is involved in regulating immunosuppressive function of regulatory T-lymphocytes (Treg) in autoimmune response [11]. Treg cells largely express FOXP3 and the alpha chain of interleukin 2 (IL-2) receptor, also known as CD25, that plays an important role in tumor immunity. Recruitment of Treg cells is involved in promoting cancer cells to escape from host protective immunity [12]. Interestingly, a number of recent studies reveal that FOXP3 is expressed not only by Treg cells but also by a range of human cancer cells [13-17], suggesting that FOXP3 expressed in cancer cells could act as a new member of TAAs. It is thus important to elucidate whether circulating antibodies to FOXP3 are increased in malignant diseases. In this study, therefore, we developed an enzyme-linked immunosorbent assay (ELISA) inhouse using the HLA-II restricted epitopes derived from FOXP3 to detect circulating anti-FOXP3 autoantibody.

\section{MATERIALS AND METHODS}

\subsection{Experimental Subjects}

A total of 271 patients who were newly diagnosed as having NSCLC were recruited for this study by the Department of Pulmonary Oncology, Third Affiliated Hospital of Harbin Medical University, Harbin, China. Of these 271 patients aged $57.4 \pm 9.2$ years, 176 were male and 95 were female. Their diagnosis was made based on radiographic examination and histological confirmation with staging information; inclusion of patients was restricted to those with adenocarcinoma $(n=158)$ and squamous carcinoma $(n=113)$ only. Blood samples were taken prior to any anticancer treatment. Two hundred twenty-seven healthy subjects, well matched in age (57.1 \pm 10.4 years), gender and smoking history, were also recruited as controls from local communities, of whom 135 were male and 92 were female. Clinical interview and radiographic examination were applied to rule out the control subjects who had history of lung cancer or any other malignant tumors. All the subjects were of Chinese Han origin and all gave written consent to participation in this study. This work was approved by the Ethics Committee of Harbin Medical University and conformed to the requirements of the Declaration of Helsinki.

\subsection{Autoantibody Testing}

Circulating $\operatorname{IgG}$ antibodies specific for FOXP3 were measured by a relative ELISA approach as described in our recent publications $[18,19]$. Briefly, the peptide antigen was synthesized by solid-phase chemistry with a purity of $>95 \%$. The synthetic peptides were dissolved in $67 \%$ acetic acid to obtain a concentration of $5 \mathrm{mg} / \mathrm{ml}$ as stock solution. The antigens were diluted with phosphatebuffered saline (PBS, Product No P4417, Sigma-Aldrich) containing $0.1 \%$ azide just before use. The optimal working solution was $7.5 \mu \mathrm{g} / \mathrm{ml}$ for the FOXP3 antigen and 20 $\mu \mathrm{g} / \mathrm{ml}$ for the control antigen as described in our previous work [18,19]. Coaster 96-Well Microtiter EIA Plates (Immuno Chemistry Technologies, USA) were halfcoated in $0.1 \mathrm{ml} /$ well of the FOXP3 antigen $(0.75 \mu \mathrm{g} /$ well) and half-coated in $0.1 \mathrm{ml} /$ well of the control antigen $(2 \mu \mathrm{g} /$ well $)$. The antigen-coated 96-well microplates were covered and incubated overnight at $4^{\circ} \mathrm{C}$. After the antigen-coated plate was washed 3 times with PBS containing $0.05 \%$ Tween-20 (PBS-T), $100 \mu 1$ plasma sample diluted 1:200 in Assay Buffer (DS98200, Invitrogen) was added to the sample wells and $100 \mu$ l Assay Buffer was added to the negative control (NC) wells. Following 3 hour incubation at room temperature, the plate was washed 3 times and $100 \mu l$ peroxidase-conjugated goat antibody to human IgG (A8667, Sigma-Aldrich) diluted 1:40000 in Assay Buffer was added to each well. After incubation at room temperature for 2 hours, color development was initiated by adding $100 \mu \mathrm{l} \mathrm{Stabi-}$ lized Chromogen (SB01, Invitrogen) and terminated 25 minutes later by adding $50 \mu 1$ Stop Solution (SS03100, Invitrogen). The measurement of optical density (OD) was completed on a microplate reader (BioTeck, USA) within 10 minutes at $450 \mathrm{~nm}$ with a reference wavelength of $620 \mathrm{~nm}$.

Each sample was tested in duplicate. To reduce the interference from a non-specific signal produced by passive absorption of various IgG antibodies in plasma to the surface of 96-well microplate, a specific binding index (SBI) was used to express the levels of circulating autoantibodies to FOXP3. SBI was calculated as follows:

$\mathrm{SBI}=[\mathrm{FOXP} 3(\mathrm{OD})-\mathrm{NC}(\mathrm{OD})] /[$ control antigen $(\mathrm{OD})$ $-\mathrm{NC}(\mathrm{OD})]$.

\subsection{Data Analysis}

The mean \pm SD in SBI was used to present data. IBM SPSS Statistics 21.0 was used to perform Student's $t$-test for the difference in SBI between the patient group and the control group. The Analyse-it software (Analyse-it Software Ltd, UK) was applied to perform receiver operating characteristic (ROC) analysis to work out the area under the ROC curve (AUC) with $95 \%$ confidence interval (CI) and the sensitivity of the ELISA antibody test against a specificity of $>90 \%$.

To minimize an intra-assay deviation, the ratio of the difference between duplicated OD values to their sum was used to assess the precision for assay of each sample. If the ratio was $>10 \%$, the test of this sample was treated as being invalid and would not be used for data analysis. The inter-assay deviation was estimated using a pooled plasma sample, namely quality control (QC) sample, which was randomly collected from $>200$ unrelated healthy subjects and tested on every $96-$-well plate. 


\section{RESULTS}

The levels of IgG autoantibody to FOXP3 were significantly higher in patients with lung cancer than control subjects $(t=4.99, P<0.0001$ for squamous cancer and $t$ $=7.31, P<0.0001$ for adenocarcinoma); both male and female patients contributed to the increased levels of $\operatorname{IgG}$ autoantibody to FOXP3 although circulating levels of anti-FOXP3 IgG was not significantly higher in female patients with squamous lung cancer (Table 1).

ROC analysis showed an AUC of 0.7 (95\%CI 0.65 $0.75, \mathrm{SE} \pm 0.024)$ and a sensitivity of $20.3 \%$ against a specificity of $90.3 \%$. As shown in Table 2, patients with NSCLC at stage 2 showed the highest AUC of 0.74 (95\% CI $0.67-0.81, \mathrm{SE}=0.037$ ), with a sensitivity of $31.4 \%$ against specificity of $90.3 \%$. Analysis of QC samples gave an inter-assay deviation of $13.3 \%$ among 45 plates tested.

\section{DISCUSSION}

Several lines of evidence have demonstrated that a range of malignant tumors overexpress FOXP3 mRNA and proteins [15], suggesting that overexpression of FOXP3 is not restricted to a particular tumor type but may indicate the existence of various malignancies in the body. In recent work, we found that circulating levels of anti-FOXP3 IgG were significantly higher in patients with esophageal cancer than health controls [18]. Functionally, FOXP3 is a transcriptional factor that has been found to play a role in repressing transcription of some oncogenes in cancer cells [20,21]. FOXP3 expression in malignant tumors may be a protective mechanism by which our body could be able to slow down the growth of cancer cells. Furthermore, we have recently found that the levels of anit-CD25 IgG antibody were significantly higher in patients with NSCLC than control subjects [19]. These observations suggest that there may be a functional alteration of Treg cells in lung cancer.

Overexpression of TAAs can stimulate the immune system to secret antibodies against themselves [22]. In this study, we developed an ELISA-based antibody test in-house for detection of circulating IgG antibody to FOXP3 and confirmed a significant increase in antiFOXP3 IgG in patients with NSCLC as compared to control subjects (Table 1), especially those at stage 2 of the malignant tumor (Table 2). This finding suggests that anti-FOXP3 antibody may be a potential biomarker for lung cancer. While testing of autoantibodies to TAAs has potential benefits for early diagnosis, the association of these autoantibodies with prognosis has been inconsistent across studies. For an example, the autoantibody to tumor-suppressor antigen p53 was reported to be associated with decreased survival rates in ovarian cancer by a couple of studies $[23,24]$, but with an increased sur-
Table 1. The levels of circulating IgG autoantibody to FOXP3 in NSCLC.

\begin{tabular}{|c|c|c|c|c|}
\hline Autoantibody & Patient (n) & Control (n) & $t^{\mathrm{b}}$ & $P$ \\
\hline \multicolumn{5}{|c|}{ Squamous } \\
\hline Male & $1.130 \pm 0.227(90)$ & $0.934 \pm 0.244(135)$ & 5.76 & $<0.0001$ \\
\hline Female & $1.076 \pm 0.230(23)$ & $1.027 \pm 0.263(92)$ & 0.81 & 0.417 \\
\hline Both & $1.119 \pm 0.228(113)$ & $0.977 \pm 0.255(227)$ & 4.99 & $<0.0001$ \\
\hline \multicolumn{5}{|c|}{ Adenocarcinoma } \\
\hline Male & $1.120 \pm 0.249(86)$ & $0.934 \pm 0.244(135)$ & 5.20 & $<0.0001$ \\
\hline Female & $1.223 \pm 0.226(72)$ & $1.027 \pm 0.263(92)$ & 5.03 & $<0.0001$ \\
\hline Both & $1.167 \pm 0.244(158)$ & $0.977 \pm 0.255(227)$ & 7.31 & $<0.0001$ \\
\hline \multicolumn{5}{|c|}{ Combined } \\
\hline Male & $1.125 \pm 0.237(176)$ & $0.934 \pm 0.244(135)$ & 6.60 & $<0.0001$ \\
\hline Female & $1.192 \pm 0.237(95)$ & $1.027 \pm 0.263(92)$ & 4.51 & $<0.0001$ \\
\hline Both & $1.147 \pm 0.238(271)$ & $0.977 \pm 0.255(227)$ & 7.67 & $<0.0001$ \\
\hline
\end{tabular}

${ }^{a}$ The antibody levels are expressed as mean \pm SD in SBI. ${ }^{b} S t u d e n t ' s ~ t$-test (two-tailed).

Table 2. ROC analysis of circulating IgG autoantibody to FOX3 in NSCLC.

\begin{tabular}{cccccc}
\hline Stage & N & AUC & $95 \%$ CI & SE & Sensitivity (\%) \\
\hline I & 121 & 0.68 & $0.62-0.74$ & 0.029 & 19.0 \\
II & 51 & 0.74 & $0.67-0.81$ & 0.037 & 31.4 \\
III & 89 & 0.72 & $0.66-0.78$ & 0.030 & 18.2 \\
IV & 10 & 0.55 & $0.38-0.73$ & 0.000 & 0 \\
All & 271 & 0.70 & $0.65-0.75$ & 0.024 & 20.3 \\
\hline
\end{tabular}

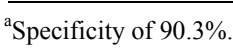

vival rate by others $[25,26]$. The utility of circulating autoantibodies to TAAs as prognostic biomarkers still needs further confirmation in large-scale clinical studies. Emerging evidence from investigation of human cancer samples suggests that there is a significant correlation between FOXP3 expression and poor prognosis of malignancies [27-29] although a recent study suggests that FOXP3 expression has a better prognostic potential in patients with NSCLC [30].

\section{CONCLUSION}

Most work reported to date has focused on quantifying either FOXP3 mRNA or proteins in tumor tissue samples. Because the antibody testing is much simple, sensitive and reproducible as compared with quantitative real-time PCR and immunohistochemical analysis, it is worth carrying out further investigation to clarify whether circulating anti-FOXP3 antibodies could serve as a prognostic biomarker. 


\section{ACKNOWLEDGEMENTS}

We thank patients and healthy volunteers for their support and participation. This work was supported by Natural Science Foundation of Heilongjiang Province, Harbin, China (grant number D201238), by YingJi Biotechnology Exploitation Co. Ltd, Shenzhen, China, and by Glory Biomedical Co. Ltd, Taipei, Taiwan.

\section{REFERENCES}

[1] Kobold, S., Lütkens, T., Cao, Y., Bokemeyer, C. and Atanackovic, D. (2010) Autoantibodies against tumorrelated antigens: Incidence and biologic significance. Human Immunology, 71, 643-651. http://dx.doi.org/10.1016/i.humimm.2010.03.015

[2] Järås, K. and Anderson, K. (2011) Autoantibodies in cancer: Prognostic biomarkers and immune activation. EXpert Review of Proteomics, 8, 577-589.

http://dx.doi.org/10.1586/epr.11.48

[3] Liu, W., Peng, B., Lu, Y. Xu, W., Qian, W. and Zhang, J.-Y. (2011) Autoantibodies to tumor-associated antigens as biomarkers in cancer immunodiagnosis. Autoimmunity Reviews, 10, 331-335. http://dx.doi.org/10.1016/j.autrev.2010.12.002

[4] Piura, E. and Piura, B. (2010) Autoantibodies to tumorassociated antigens in breast carcinoma. Journal of Oncology, 2010, 264926.

http://dx.doi.org/10.1155/2010/264926

[5] Piura, E. and Piura, B. (2011) Autoantibodies to tailormade panels of tumor-associated antigens in breast carcinoma. Journal of Oncology, 2011, 982425.

[6] Zhong, L., Coe, S.P., Stromberg, A.J., Khattar, N.H., Jett, J.R. and Hirschowitz, E.A. (2006) Profiling tumor-associated antibodies for early detection of non-small cell lung cancer. Journal of Thoracic Oncology, 1, 513-519. http://dx.doi.org/10.1097/01243894-200607000-00003

[7] Chapman, C., Murray, A., Chakrabarti, J., Thorpe, A., Woolston, C., Sahin, U., Barnes, A. and Robertson, J. (2007) Autoantibodies in breast cancer: Their use as an aid to early diagnosis. Annals of Oncology, 18, 868-873. http://dx.doi.org/10.1093/annonc/mdm007

[8] Tan, H.T., Low, J., Lim, S.G. and Chung, M.C. (2009) Serum autoantibodies as biomarkers for early cancer detection. FEBS Journal, 276, 6880-6904. http://dx.doi.org/10.1111/j.1742-4658.2009.07396.x

[9] Chapman, C.J., Healey, G.F., Murray, A., Boyle, P., Robertson, C., Peek, L.J., Allen, J., Thorpe, A.J., Hamilton-Fairley, G., Parsy-Kowalska, C.B., MacDonald, I.K., Jewell, W., Maddison, P. and Robertson, J.F. (2012) EarlyCDT®-Lung test: Improved clinical utility through additional autoantibody assays. Tumor Biology, 33, 13191326. http://dx.doi.org/10.1007/s13277-012-0379-2

[10] Coffer, P.J. and Burgering, B.M. (2004) Forkhead-box transcription factors and their role in the immune system. Nature Reviews Immunology, 4, 889-899. http://dx.doi.org/10.1038/nri1488

[11] Redpath, M., Xu, B., van Kempen, L.C. and Spatz, A. (2011) The dual role of the X-linked FoxP3 gene in hu- man cancers. Molecular Oncology, 5, 156-163. http://dx.doi.org/10.1016/j.molonc.2011.03.001

[12] Olkhanud, P.B., Damdinsuren, B., Bodogai, M., Gress, R.E., Sen, R., Wejksza, K., Malchinkhuu, E., Wersto, R.P. and Biragyn, A. (2011) Tumor-evoked regulatory B cells promote breast cancer metastasis by converting resting $\mathrm{CD}^{+} \mathrm{T}$ cells to T-regulatory cells. Cancer Research, 71, 3505-3515. http://dx.doi.org/10.1158/0008-5472.CA-N-10-4316

[13] Ebert, L.M., Tan, B.S., Browning, J., Svobodova, S., Russell, S.E., Kirkpatrick, N., Gedye, C., Moss, D., Ng, S.P., MacGregor, D., Davis, I.D., Cebon, J. and Chen, W. (2008) The regulatory T cell-associated transcription factor FoxP3 is expressed by tumor cells. Cancer Research, 68, 3001-3009. http://dx.doi.org/10.1158/0008-5472.CAN-07-5664

[14] Karanikas, V., Speletas, M., Zamanakou, M., Kalala, F., Loules, G., Kerenidi, T., Loules, G., Kerenidi, T., Barda, A.K., Gourgoulianis, K.I. and Germenis, A.E. (2008) Foxp3 expression in human cancer cells. Journal of Translational Medicine, 6, 19. http://dx.doi.org/10.1186/1479-5876-6-19

[15] Yoshii, M., Tanaka, H., Ohira, M., Muguruma, K., Iwauchi, T., Lee, T., Sakurai, K., Kubo, N., Yashiro, M., Sawada, T. and Hirakawa, K. (2012) Expression of Forkhead box P3 in tumour cells causes immunoregulatory function of signet ring cell carcinoma of the stomach. British Journal of Cancer, 106, 1668-1674. http://dx.doi.org/10.1038/bjc.2012.141

[16] Triulzi, T., Tagliabue, E., Balsari, A. and Casalini, P. (2013) FOXP3 expression in tumor cells and implications for cancer progression. Journal of Cellular Physiology, 228, 30-35. http://dx.doi.org/10.1002/jcp.24125

[17] Wang, P., Sidney, J., Kim, Y., Sette, A., Lund, O., Nielsen, M., Nielsen, M. and Peters, B. (2010) Peptide binding predictions for HLA DR, DP and DQ molecules. BMC Bioinformatics, 11, 568. http://dx.doi.org/10.1186/1471-2105-11-568

[18] Ye, L., Guan, S., Zhang, C., Lee, K-H., Sun, L., Wei, J. and Liu, B. (2013) Circulating autoantibody to FOXP3 may be a potential biomarker for esophageal squamous cell carcinoma. Tumor Biology, 34, 1873-1877. http://dx.doi.org/10.1007/s13277-013-0729-8

[19] Ye, L., Li, X., Sun, S., Guan, S., Wang, M., Guan, X., Lee, K-H., Wei, J. and Liu, B. (2013) A study of circulating anti-CD25 antibodies in non-small cell lung cancer. Clinical and Translational Oncology, 5, 633-637. http://dx.doi.org/10.1007/s12094-012-0980-2

[20] Zuo, T., Wang, L., Morrison, C., Chang, X., Zhang, H., Li, W., Wang, L., Zheng, P. and Liu, Y (2007) FOXP3 is an $\mathrm{X}$-linked breast cancer suppressor gene and an important repressor of the HER-2/ErbB2 oncogene. Cell, 129, 1275-1286. http://dx.doi.org/10.1016/j.cell.2007.04.034

[21] Wang, L., Liu, R., Li, W., Chen, C., Katoh, H., Chen, G.Y., McNally, B., Lin, L., Zhou, P., Zuo, T., Cooney, K.A., Liu, Y. and Zheng, P. (2009) Somatic single hits inactivate the $\mathrm{X}$-linked tumor suppressor FOXP3 in the prostate. Cancer Cell, 16, 336-346. http://dx.doi.org/10.1016/j.ccr.2009.08.016 
[22] Chen, Y.T., Scanlan, M.J., Sahin, U., Türeci, O., Gure, A.O. and Tsang, S. (1997) A testicular antigen aberrantly expressed in human cancers detected by autologous antibody screening. Proceedings of the National Academy of Sciences, 94, 1914-1918. http://dx.doi.org/10.1073/pnas.94.5.1914

[23] Mayerhofer, K., Tempfer, C., Kucera, E., Hefler, L., Zeisler, H., Kainz, C., Zeillinger, R. and Sliutz, G. (1999) Humoral p53 antibody response is a prognostic parameter in ovarian cancer. Anticancer Research, 19, 875-878.

[24] Abendstein, B., Daxenbichler, G. and Windbichler, G. (2000) Predictive value of uPA, PAI-1, HER-2 and VEGF in the serum of ovarian cancer patients. Anticancer Research, 20, 569-572.

[25] Goodell, V., Salazar, L.G., Urban, N., Drescher, C.W., Gray, H., Swensen, R.E., McIntosh, M.W. and Disis, M.L. (2006) Antibody immunity to the p53 oncogenic protein is a prognostic indicator in ovarian cancer. Journal of Clinical Oncology, 24, 762-768. http://dx.doi.org/10.1200/JCO.2005.03.2813

[26] Anderson, K.S., Wong, J., Vitonis, A., Crum, C.P., Sluss, P.M., Labaer, J., Cramer, D. and Cramer, D. (2010) p53 autoantibodies as potential detection and prognostic bio- markers in serous ovarian cancer. Cancer Epidemiology, Biomarkers \& Prevention, 19, 859-868. http://dx.doi.org/10.1158/1055-9965.EPI-09-0880

[27] Wolf, A.M., Rumpold, H., Wolf, D., Gastl, G., Reimer, D., Jenewein, N., Marth, C. and Zeimet, A.G. (2007) Role of forkhead box protein 3 expression in invasive breast cancer. Journal of Clinical Oncology, 25, 4499-4500. http://dx.doi.org/10.1200/JCO.2007.13.2092

[28] Deleeuw, R.J., Kost, S.E., Kakal, J.A. and Nelson, B.H. (2012) The prognostic value of FoxP3 + tumor-infiltrating lymphocytes in cancer: A critical review of the literature. Clinical Cancer Research, 18, 3022-3029. http://dx.doi.org/10.1158/1078-0432.CCR-11-3216

[29] Wang, G., Liu, G., Liu, Y., Li, X. and Su, Z. (2012) FOXP3 expression in esophageal cancer cells is associated with poor prognosis in esophageal cancer. Hepatogastroenterology, 59, 2186-2191.

[30] Tao, H., Mimura, Y., Aoe, K., Kobayashi, S., Yamamoto, H., Matsuda, E., Okabe, K., Matsumoto, T., Sugi, K. and Ueoka, H. (2012) Prognostic potential of FOXP3 expression in non-small cell lung cancer cells combined with tumor-infiltrating regulatory $\mathrm{T}$ cells. Lung Cancer, 75, 95-101. http://dx.doi.org/10.1016/j.lungcan.2011.06.002 